\title{
USO DA TERRA E FEIÇÕES MORFOLÓGICAS NO BAIXO CURSO DO RIO SEPOTUBA NO TRECHO ENTRE A FAZENDA AJUSTA CONTA E A BAÍA DA SANFONA, REGIÃO SUDOESTE DE MATO GROSSO
}

\author{
Carolina da Costa Tavares ${ }^{(a)}$, Célia Alves de Souza ${ }^{(b)}$, Vinicius Neves da Silva ${ }^{(c)}$, Evanil \\ Rocha $^{(\mathrm{d})}$ \\ (a) Graduanda em Geografia pela Universidade do Estado do Mato Grosso, carolina_tavares_5@hotmail.com \\ (b) Professora da Universidade do Estado de Mato Grosso Departamento de Geografia, celiaalvesgeo@globo.com

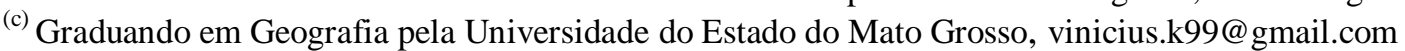 \\ ${ }^{\text {(d) }}$ Graduanda em Geografia pela Universidade do Estado do Mato Grosso, evanilmt030@hotmail.com
}

\section{EIXO: BACIAS HIDROGRÁFICAS E RECURSOS HÍDRICOS: ANÁLISE, PLANEJAMENTO E GESTÃO}

\begin{abstract}
Resumo
O objetivo do estudo foi analisar a evolução espaço-temporal das feições morfológicas e apresentar as características ambientais do baixo curso do rio Sepotuba no trecho entre a fazenda Ajusta Conta e a baía Sanfona, região Sudoeste de Mato Grosso. Para a confecção dos mapas utilizou a imagem de satélite LandSat 5 TM e LandSat 8 OLI e as ferramentas do Sistema de Informações Geográfico (GIS / SIG) por software ArcGis 9.3 . No trecho estudado o rio possui padrão meandrante, a planície de inundação com abrangência de $35.804 \mathrm{~km}^{2} \mathrm{em} \mathrm{1986}$, diminuindo para $26.317 \mathrm{~km}^{2} \mathrm{em} 2016$. Na margem esquerda em 1986 identificou-se uma área preservada de cobertura vegetal de $9,789379 \mathrm{~km}^{2}$, e em 2016 essa vegetação foi substituída por pastagem. Observou-se, no período, a presença de canais secundários e lagoas, registrando algumas alterações como: diminuição, aumento, surgimento e desaparecimento de lagoas.
\end{abstract}

Palavras chave: Feições morfológicas, rio Sepotuba, espaço temporal.

\section{INTRODUÇÃO}

A bacia de drenagem é uma área da superfície terrestre que drena água, sedimentos e materiais dissolvidos para uma saída comum, num determinado ponto de um canal fluvial. O limite de uma bacia de drenagem é conhecido como divisor de drenagem ou divisor de águas. (NETTO, 2008).

Segundo Carvalho (1984) a bacia hidrográfica do rio Sepotuba drena $11.460 \mathrm{~km}^{2}$, e apresenta vegetação densa. Sua planície de inundação é limitada, mas próximo à foz, a área de inundação é extensa com vários meandros abandonados.

Os canais meandrantes são encontrados principalmente nos rios que percorrem regiões quentes e úmidas em terrenos planos, possuem curvas sinuosas, escavando na margem côncava e depositando na margem convexa (CHRISTOFOLETTI, 1980).

As mudanças espaço-temporais das feições morfológicas fluviais ocorrem, de modo geral, principalmente devido à erosão e à deposição de sedimentos. A sedimentação de acreção lateral 
consiste na sucessiva acumulação lateral de sedimentos, principalmente no lado interno da curva do canal meandrante. Em virtude da contínua erosão da margem côncava e sedimentação na margem convexa, o canal mantém-se em constante migração lateral, estabelecendo aspecto bastante dinâmico ao ambiente fluvial (CHRISTOFOLETTI, 1981; BIGARELLA, 2003).

Para Kellerhald et al. (1976) e Dietrich (1985), as características da calha estão, em sua maioria, associadas aos processos de erosão e deposição. Os depósitos de sedimentos pertencem a diferentes categorias, como os que se desenvolvem no eixo central, ou seja, os bancos ou barras centrais (mid channel bar), as barras laterais (channel side bar e point bars), barras submersas e ilhas fluviais.

A planície de inundação é uma faixa do vale fluvial composta de sedimentos aluviais, bordejando o curso de água, e periodicamente inundadas pelas águas de transbordamento provenientes do rio (CHRISTOFOLETTI, 1980).

O objetivo do estudo foi analisar a evolução espaço-temporal das feições morfológicas e apresentar as características ambientais do baixo curso do rio Sepotuba no trecho entre a fazenda Ajusta Conta e a baía Sanfona, região Sudoeste de Mato Grosso.

\section{MATERIAL E MÉTODOS}

\section{1.Área de Estudo}

A área de estudo localiza-se no trecho entre a Fazenda Ajusta Conta e à Baia Sanfona, no baixo do rio Sepotuba na região Sudoeste de Mato Grosso. Encontra-se entre as coordenadas geográficas de $15^{\circ} 41^{\prime} 20.76^{\prime \prime}$ e $15^{\circ} 44^{\prime} 49.51^{\prime \prime} \mathrm{S} 57^{\circ} 37^{\prime} 32.72^{\prime \prime}$ e 5741’49.69” W, com área total de $31,15 \mathrm{~km}^{2}$ (Figura $1)$.

\subsection{Características Ambientais}

A litologia da área de estudo é composta pela Formação Pantanal e por aluviões atuais. A Formação Pantanal apresenta sedimentos finos a grosseiros semiconsolidados, depósitos fluviais e lacustres em áreas periodicamente ou ocasionalmente inundáveis (RADAMBRASIL, 1982). De acordo com Souza, Lani e Sousa (2006) a Formação Pantanal é constituída por areias inconsolidadas, de granulometria fina a média, intercalada por materiais síltico-argilosos. Os aluviões atuais são depósitos das planícies de inundação.

A geomorfologia desta área apresenta planície fluvial, que é uma área aplanada resultante da acumulação fluvial de um período ou permanentemente alagada; e terraço fluvial, sendo este um patamar esculpido pelo próprio rio com declive fraco voltado para o leito com cobertura aluvial. 
XVII Simpósio Brasileiro

de Geografia Fisica Aplicada

I Congresso Nacional

de Geografia Fisica

\section{OS DESAFIOS DA GEOGRAFIA FISICA NA FRONTEIRA DO CONHECIMENTO \\ Instituto de Geociências - Unicamp \\ Campinas - SP \\ 28 de Junho à 02 de Jutho de 2017}

Registrou-se a ocorrência de Gleissolo Háplico Tb Eutrófico. São solos rasos, pouco desenvolvidos, orgânico-minerais, com características de locais planos e abaciados, sujeitos a alagamentos constantes e periódicos, marcados por uma série de terraços e planícies fluviais e recobertos por vegetação de várzea (RADAMBRASIL, 1982).
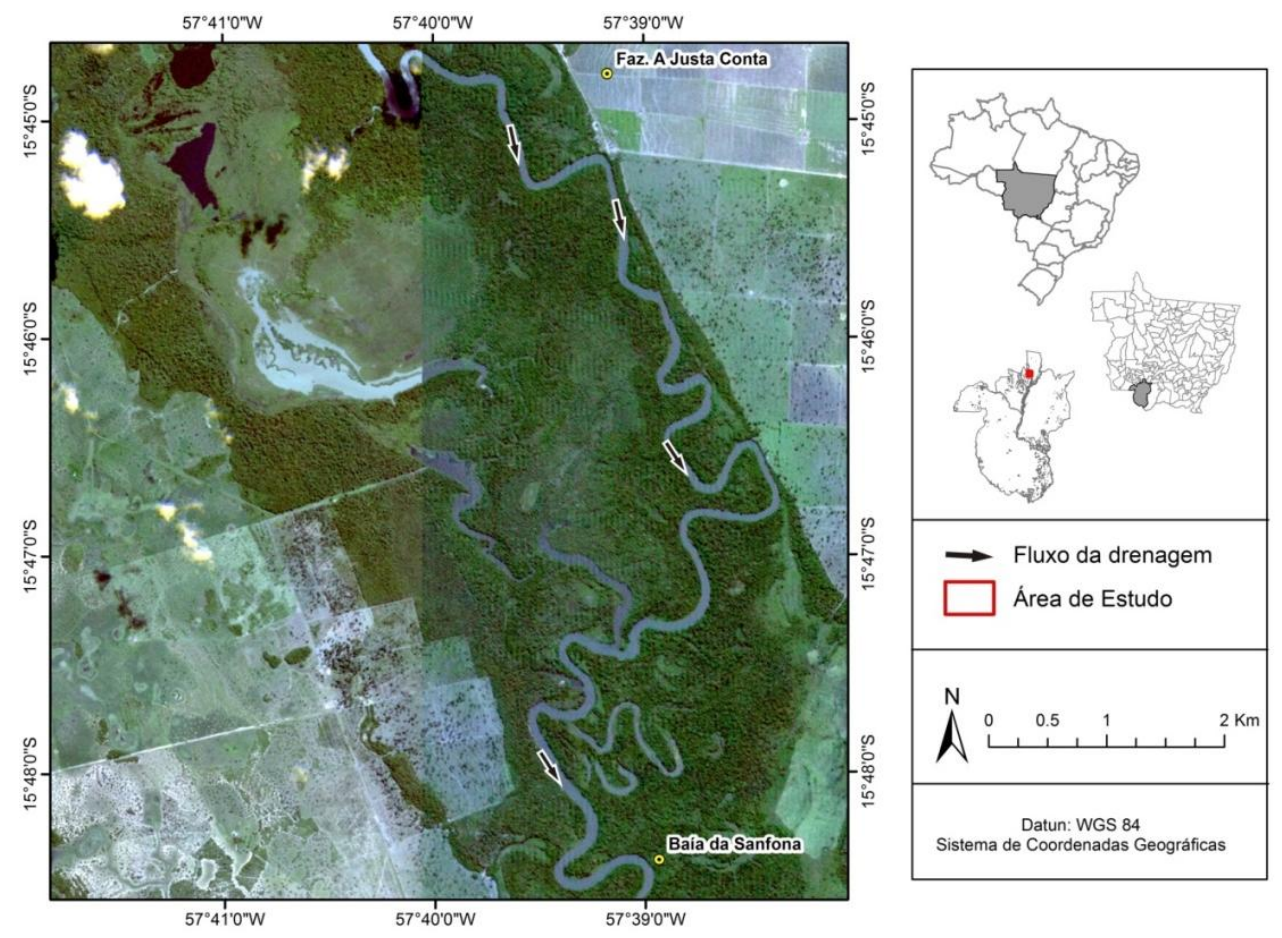

Figura 01 - Localização da área de estudo no rio Sepotuba no trecho entre a fazenda Ajusta Conta e a Baía Sanfona

A granulometria predominantemente fina, associada às baixas declividades inferiores a 1\% (SEPLAN, 2000), favorece maior retenção e acúmulo de água por um período maior, na planície de inundação. No período de estiagem, a concentração elevada de argila resseca e formam-se fendas, tornando as margens do canal fluvial vulnerável à erosão mecânica.

Quanto à vegetação foram identificadas Floresta Aluvial, que foi observada ao longo do rio Sepotuba, em áreas inundáveis ou sujeitas à inundação. Esta formação florestal ribeirinha é diversificada, sendo que suas principais características variam de acordo com sua localização na formação aluvial. São vegetações de pequeno porte, adaptáveis ao encharcamento do solo durante o período das cheias (RADAMBRASIL, 1982).

\subsection{Procedimento metodológico}

Foram confeccionados mapas de localização e temático com utilização de Sistema de Informações Geográfico (GIS / SIG) por software ArcGis 9.3 licenciado, sendo interpretado e projetado os mapas: 
XVII Simpósio Brasileiro de Geografia Fisica Aplicada

I Congresso Nacional de Geografia Fisica

\section{OS DESAFIOS DA GEOGRAFIA FISICA NA FRONTEIRA DO CONHECIMENTO \\ Instituto de Geociências - Unicamp \\ Campinas - SP \\ 28 de Junho à 02 de julho de 2017}

- Localização: Foi utilizado imagens de satélite LANDSAT 8 OLI com 30 metros de resolução espacial, posteriormente a imagem passou pela composição de bandas 4, 5 e 6 RGB em falsa cor, logo após redimecionado raster para 15 metros de resolução pela função Pan Sharpen através da banda 8 (Pan), inserido arquivo vetorial sobre o mesmo delimitando a área de estudo, recortando o raster através da função Extract by Mask. Confeccionado layout do mapa.

- Temático - espaço temporal: Definidas as datas para analise espaço temporal, foram obtidas Imagens/raster dos satélites LandSat 5 TM e LandSat 8 OLI. Posteriormente a criação do arquivo vetorial, constituindo classes de análise e classificado por sobre cada feição sobre a área de estudo, após a vetorização, foi calculado a área dos polígonos em quilômetros quadrados. O mesmo processo seguiu de forma semelhante para todas as imagens. E assim, confeccionando layout do mapa, seguindo normativas cartográficas.

\section{RESULTADOS E DISCUSSÃO}

No trecho estudado o rio possui padrão meandrante, com a planície de inundação com dimensão de $35.804 \mathrm{~km}^{2}$ em 1986, diminuindo para $26.317 \mathrm{~km}^{2}$, devido o desmatamento. A ocorrência de planície de inundação está vinculada aos aspectos do baixo curso da bacia, como baixa declividade, tipo de solo e regime sazonal de cheia e seca. Na margem esquerda em 1986 registrou uma área preservada, com cobertura vegetal $\left(9,789379 \mathrm{~km}^{2}\right)$, em 2016 essa vegetação foi substituída por pastagem (figura

2). Observou a presença de canais secundários e lagoas.
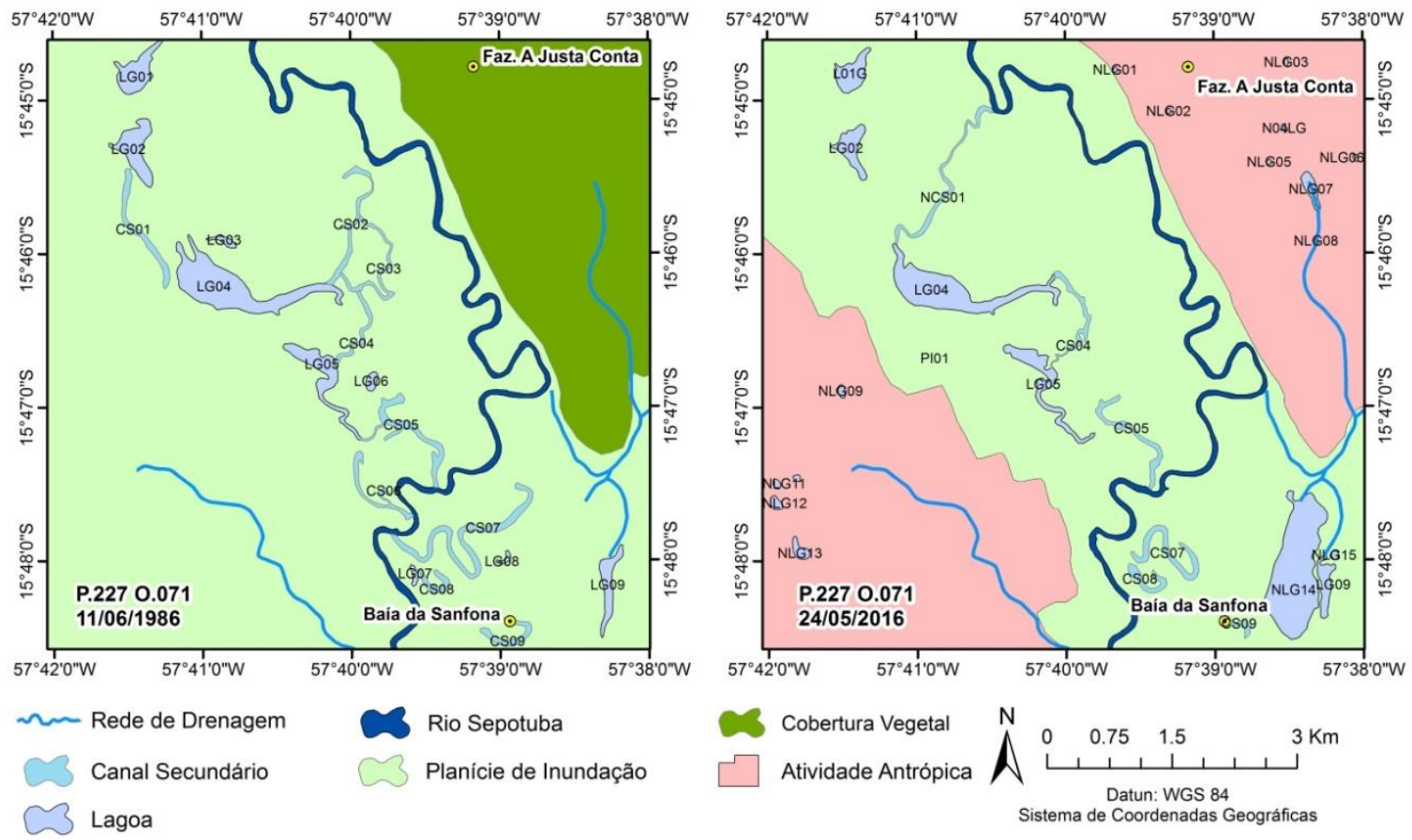

DOI - 10.20396/sbgfa.v1i2017.2122 - ISBN 978-85-85369-16-3 
XVII Simpósio Brasileiro

de Geografia Fisica Aplicada

I Congresso Nacional

de Geografia Física
OS DESAFIOS DA GEOGRAFIA FISICA NA FRONTEIRA DO CONHECIMENTO

Instituto de Geociências - Unicamp

Campinas - SP

28 de Junho à 02 de julho de 2017

Figura 2- mapa espaço temporal das feições das do baixo curso do rio Sepotuba no trecho entre a fazenda Ajusta Conta e a baía Sanfona, região Sudoeste de Mato Grosso.

Em 1986 foi registrada a ocorrência de nove lagoas, a área das lagoas variou 0,0140 a 0,563 km². Em 2016 quatro lagoas desapareceram, todas as lagoas diminuíram sua dimensão e surgiram 15 novas lagoas, sendo importante mencionar que a maioria das lagoas que surgiram encontra-se na área que foi desmatada, como houve um aumento de áreas antropizadas, esse fator pode ter contribuído para que ocorresse tal mudança. Nascimento et.al (2005) constatou o surgimento de várias lagoas em áreas que foram desmatadas ao longo da BR 070. O desaparecimento de algumas lagoas pode estar relacionado ao processo de colmatação, considerando o processo intenso de sedimentação no baixo curso.

A origem dos canais secundários está associada aos antigos leitos e canais de conexão entre lagoas, com classificação regional de vazante. Verificou-se nove canais secundários em 1986, o tamanho dos canais secundários variou de 0,0421 a $0,2259 \mathrm{~km}^{2}$.

\section{CONCLUSÃO}

As informações obtidas apontam a evolução da degradação no baixo curso do rio Sepotuba, com retirada da vegetação nativa, inclusive em áreas de planície. Mostra a diminuição da dimensão da área e unidades de lagoas e canais secundários, registando também o desaparecimento (por colmatação) dessas feições (lagoas e canais secundários) associadas ao processo de sedimentação em função do uso e ocupação da bacia hidrográfica.

\section{REFERÊNCIAS BIBLIOGRÁFICAS}

BIGARELLA, J.J. Estrutura e origem das paisagens tropicais e subtropicais. Florianópolis: Ed. Da UFSC, 2003. 877-1435p.

BRASIL. Ministério das Minas e Energia. Secretaria-Geral. Projeto RADAMBRASIL. FOLHA SD.21 Cuiabá: geologia, geomorfologia, pedologia, vegetação e uso potencial da terra. Rio de Janeiro, 1982. 33, 147, 409, p.

CARVALHO, N. O. Hidrologia da Bacia do Alto Paraguai. In: Simpósio sobre recursos naturais e sócioseconômico do pantanal, 1... 1984, Corumbá. Anais... Brasília: EMBRAPA-DDT, 1984. p. 43-49.

CHRISTOFOLETTI, A. Geomorfologia. São Paulo: Editora Blucher, 1980. 188p.

CHRISTOFOLETTI, A. Geomorfologia Fluvial. São Paulo: Editora Blucher, 1981.

CUNHA, S. B. da. GUERRA, A.J.T. Degradação Ambiental. In: Geomorfologia e Meio Ambiente. Rio de Janeiro. Bertrand Brasil. Capítulo 7, 2004.

DIETRICH, W. E. Mechanics of flow and sediment in river bends. In: PETTS, G. (Ed.). Rivers a landscape. Edward Arnold, 1985. 158-174p.

KELLERHALD, R. CHURCH, M. BRAY, D. Classification and analyses of river processes. American Society of Civil Engeneers Proceding. Journal of the Hidraulies Division, 1979. 813-829.

NETTO, Ana L. Coelho. Bacia de drenagem: um sistema hidrogeomorfológico. In: GUERRA, A.J.T.; CUNHA, S.B da. (Orgs). Geomorfologia: uma atualização de bases e conceitos. -8.ed.- Rio de Janeiro: Bertrand Brasil, 2008. 97-8p. 
NASCIMENTO E. L., SOUZA C. A., SOARES J. C. O. Evolução espaço-temporal das lagoas à margem da BR 070 e MT 174, no trecho entre a ponte Marechal Rondon e o Distrito do Caramujo. In SOUZA C. A., SOUSA J. B. (Orgs) Estudos Geoambientais na Bacia Hidrográfica do Alto Paraguai. Editora da Unemat. 2005. 103$125 \mathrm{p}$.

SEPLAN. Zoneamento socioeconômico-ecológico: Levantamento de reconhecimento de baixa intensidade dos solos do Estado de Mato Grosso. Nível compilatório. Cuiabá-MT, 2000. 121 p.

SOUZA, C. A. LANI, J. L. SOUSA, J. B. Origem e evolução do pantanal mato-grossense. In: VI Simpósio Nacional de Geomorfologia- Geomorfologia Tropical e Subtropical: processos, métodos e técnicas. Goiânia, 6 a 10 de setembro de 2006. 